
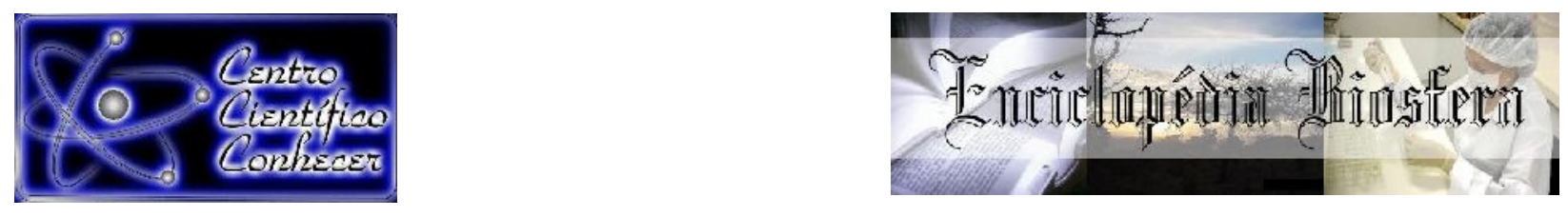

\title{
DESEMPENHO ZOOTÉCNICO E RENDIMENTO DE CARCAÇA DE LINHAGENS DE FRANGOS DE CORTE CRIADAS SOB CONDIÇÕES AMBIENTAIS DA AMAZÔNIA OCIDENTAL
}

Gilcineide Araújo Pires ${ }^{1}$, Marcelo Bastos Cordeiro ${ }^{2}$, Henrique Jorge de Freitas ${ }^{3}$, Suelen Ferreira da Costa Rodrigues ${ }^{1}$, Antonia Mariana do Nascimento ${ }^{1}$

1 - Doutoranda do Programa de Pós-graduação em Produção e Sanidade Animal Sustentável na Amazônia Ocidental da Universidade Federal do Acre. Rio Branco, AC - Brasil (gilce.pires@gmail.com)

2 - Professor Doutor da Universidade Federal dos Vales do Jequitinhonha e Mucuri, Instituto de Ciências Agrárias. Unaí, MG - Brasil

3 - Professor Doutor do Programa de Pós-graduação em Produção e Sanidade

Animal Sustentável na Amazônia Ocidental da Universidade Federal do Acre. Rio Branco, AC - Brasil

Recebido em: 06/04/2019 - Aprovado em: 10/06/2019 - Publicado em: 30/06/2019 DOI: 10.18677/EnciBio_2019A48

\section{RESUMO}

Objetivou-se avaliar o efeito do microclima sobre o desempenho zootécnico e o rendimento de carcaça de duas linhagens comerciais de frangos de corte criadas nas condições ambientais da Amazônia ocidental. Foram utilizados 280 frangos das linhagens Cobb e Ross, distribuídas em delineamento de blocos ao acaso, considerando o sexo como o critério de blocagem, composto de dois tratamentos e sete repetições. As comparações entre médias das variáveis foram feitas pelo teste $\mathrm{F}$, a $5 \%$ de probabilidade. No decorrer do experimento, a cada sete dias, foram analisados os parâmetros: peso vivo, o consumo de ração, a conversão alimentar, a eficiência alimentar e a viabilidade. Aos 63 dias, foram selecionadas 10\% de cada parcela das aves para avaliação de rendimento de carcaça. Durante o período experimental foram feitas leituras de temperatura e umidade relativa do ar para caracterização do microclima, as quais foram submetidas a análise por meio do software Pro HOBOware ${ }^{\circledR}$. Observou-se uma grande oscilação de temperatura do ar e umidade relativa. A linhagem Cobb teve peso vivo superior à linhagem Ross, a partir dos 21 dias de idade e maior consumo de ração a partir dos 28 dias. Nos parâmetros de conversão alimentar, eficiência alimentar e viabilidade, não houve efeito das linhagens. Não houve diferenças significativas entre as linhagens em termos de rendimento de carcaça. Baixas temperaturas de conforto durante as primeiras semanas e altas temperaturas de conforto nas semanas subsequentes, associadas a grande oscilação da umidade relativa do ar, prejudicaram 0 desempenho e o rendimento produtivo dos frangos.

PALAVRAS-CHAVE: Ambiente, Aves, Temperatura, Umidade Relativa. 


\title{
PRODUCTION PERFORMANCE AND CARCASS YIELD OF TWO BROILER LINES REARED UNDER THE ENVIRONMENTAL CONDITIONS OF WESTERN AMAZON
}

\begin{abstract}
The aim of this study was to evaluate the effect of microclimate on production performance and carcass yield of two lines of commercial broilers reared in the environmental conditions of western Amazon. A total of 280 hens of the Cobb and Ross lines were distributed in a randomized block design, in which the sex was considered the block factor, with two treatments and seven replicates per treatment. The evaluated parameters were live weight, feed intake, feed conversion, feed efficiency, and viability. At 63 days, $10 \%$ of the birds from each plot were selected for an evaluation of carcass yield, prime cuts, abdominal fat content, and edible viscera. During the experimental period, temperature and relative humidity readings were obtained to characterize the microclimate. A large variation was observed in air temperature and relative humidity throughout the experimental period. The Cobb line had a higher live weight than the Ross line from 21 days of age, and lower feed intake after 28 days of age. No effect of lines was detected on the feed conversion, feed efficiency, or viability parameters. There were no significant differences between the lines in terms of carcass yield, edible viscera, prime cuts, or abdominal fat. Low comfort temperatures during the first weeks and high comfort temperatures in the subsequent weeks, associated with a high fluctuation of the air relative humidity, compromised the production performance of the broilers.
\end{abstract}

KEYWORDS: Ambience, birds, relative humidity, temperature.

\section{INTRODUÇÃO}

A avicultura de corte no Brasil visa à máxima produtividade de carne com menor custo e tempo de produção reduzido. Dessa forma, busca-se conciliar o uso de aves geneticamente melhoradas, dietas balanceadas nutricionalmente, com um ambiente de criação termicamente adequado às necessidades das aves. Os programas de melhoramento genético necessitam de constantes informações referentes a ganho de peso, a conversão alimentar e a viabilidade de cada linhagem e de seus cruzamentos. A partir da avaliação dessas características é possível a melhoria do material genético dos frangos de corte. Os métodos empregados para verificar a eficiência produtiva são os fatores que definem a qualidade da linhagem (API et al., 2017).

$\mathrm{Na}$ produção de frangos de corte, as linhagens predominantes apresentam características de velocidade de crescimento e rendimento de carne (LITZ et al., 2014). Além do metabolismo acelerado, possuem uma baixa eficiência nos mecanismos de perda de calor, para diminuir a temperatura corpórea. São animais homeotérmicos e quando expostos a altas temperaturas, reduzem a ingestão de alimento, que consequentemente, prejudica a taxa de crescimento e o rendimento produtivo (DA COSTA et., 2017).

As aves procuram controlar sua temperatura corporal através de mecanismos comportamentais e fisiológicos. Entretanto, nas primeiras semanas de vida, estas não apresentam o sistema termorregulador completamente desenvolvido (CORDEIRO et al., 2010). Dessa forma, se forem inseridas em ambientes com condições de estresse térmico, ocorrerá um desperdício de energia que será gasto na termorregulação (LI et al., 2015). 
No Brasil, que apresenta clima tropical, a produção avícola enfrenta constante conflito com as condições ambientais, mais especificamente com o calor acima do nível de conforto dos animais. No caso da região Amazônica, as temperaturas médias elevadas e alta umidade durante a maior parte do ano (MARQUES et al., 2017), comprometem o processo respiratório das aves, influenciando negativamente na troca de calor com o ambiente.

Para verificar se o ambiente de criação é favorável ao conforto térmico das aves, é necessário avaliar as respostas produtivas, fisiológicas e comportamentais. $O$ frango de corte quando submetido a diferentes intensidades e durações de estresse, pode variar o consumo de ração e de água, ganho de peso e a conversão alimentar (MARQUES et al., 2017).

Assim, a escolha de linhagens cada vez mais adaptadas às regiões de clima tropical e instalações que proporcionam ainda mais conforto aos animais são fundamentais para o progresso da atividade avícola. Sem falar no manejo, que diminui os efeitos negativos do ambiente sobre as aves, e estes devem ser seguidos, a fim de aumentar a produção avícola nacional (MARQUES et al., 2017).

Nesse contexto, este trabalho objetivou avaliar o desempenho zootécnico e os rendimentos de carcaça e cortes de duas linhagens comerciais de frangos de corte, a fim de identificar quais das linhagens estudadas proporcionam maiores vantagens de produção na região Amazônia ocidental.

\section{MATERIAL E MÉTODOS}

O experimento foi conduzido no Setor de Avicultura da Universidade Federal do Acre, em Rio Branco, Acre, no período de 21 de julho a 23 de setembro de 2016. Todos os procedimentos realizados neste experimento foram aprovados pelo Comitê de Ética no Uso de animais (CEUA) da Universidade Federal do Acre - UFAC, Rio Branco, Acre, Protocolo no 91/2015.

Os frangos foram alojados, em um galpão experimental com dimensões de 80 $\mathrm{m}^{2}$, dividido em 32 boxes, cada um com as dimensões de 2,0 m²; piso e muretas laterais de concreto, pilares e tesoura de madeira, cercado com tela de arame, bem como as divisórias internas; orientação Leste-Oeste; pé direito de 2,8 m, cobertura de alumínio e lanternim de fibrocimento.

Para caracterização das condições climáticas do microclima, foram realizadas medições de temperatura e umidade relativa do ar em dois pontos do galpão, utilizando dataloggers conjugados Hobos, da empresa ONSET Corp, em intervalos de 15 minutos, durante todo o período experimental. Posteriormente, os dados foram submetidos a análise por meio do software Pro HOBOware $\AA$, o que resultou na média de temperatura e umidade relativa do ar do período experimental correspondente a cada semana.

Foram utilizados 280 frangos das linhagens Cobb e Ross, machos e fêmeas. As aves foram distribuídas em delineamento de blocos ao acaso, considerando o sexo como o critério de blocagem, composto de dois tratamentos (linhagens: Cobb e Ross) e sete repetições.

Cada boxe, alojou 10 aves ( 5 aves $\left./ \mathrm{m}^{2}\right)$, foi equipado com um comedouro tubular, um bebedouro semiautomático. As aves receberam rações isonutritivas e isoenergética, seguindo as recomendações nutricionais das aves de acordo com o Rostagno et al. (2011), conforme a fase. O manejo produtivo foi realizado duas vezes ao dia, mantendo água limpa e ração à vontade. 
Durante a condução do experimento procedeu-se à pesagem das aves e das rações no $7^{\circ}, 14^{\circ} 21^{\circ}, 28^{\circ}, 35^{\circ}, 42^{\circ}, 49^{\circ}, 56^{\circ}$ e $63^{\circ}$ dia de idade para avaliação do desempenho zootécnico. Calcularam-se o peso vivo (PV), o consumo de ração (CR), a conversão alimentar (CA), a eficiência alimentar ( $E A)$ e a viabilidade $(V)$. O número de aves mortas foi registrado diariamente, sendo a porcentagem calculada em relação ao número inicial de aves alojadas, para mensuração da viabilidade.

Aos 63 dias, foram selecionadas $10 \%$ das aves de cada parcela das aves para avaliação de rendimento de carcaça. O rendimento de carcaça (sem cabeça, pés e vísceras comestíveis) foi determinado em relação ao peso ao vivo (após jejum de 12 horas) e o rendimento de cortes nobres (peito, coxas e sobrecoxas). Teor de gordura abdominal, sendo considerada a gordura presente na região da cloaca e aquela aderida a moela e rendimento de vísceras (intestino, fígado, coração e moela) em relação ao peso da carcaça eviscerada.

As comparações entre médias das variáveis foram feitas pelo teste $\mathrm{F}$, a $5 \%$ de probabilidade. As análises estatísticas das variáveis estudadas foram feitas utilizando-se o programa SISVAR versão 5.6 (Sistema para Análise Estatística), desenvolvido por Ferreira (2014).

\section{RESULTADOS E DISCUSSÃO}

Os resultados da temperatura do ar e da umidade relativa do ar e as respectivas faixas de conforto das aves estão apresentados nas Figuras 1 e 2.

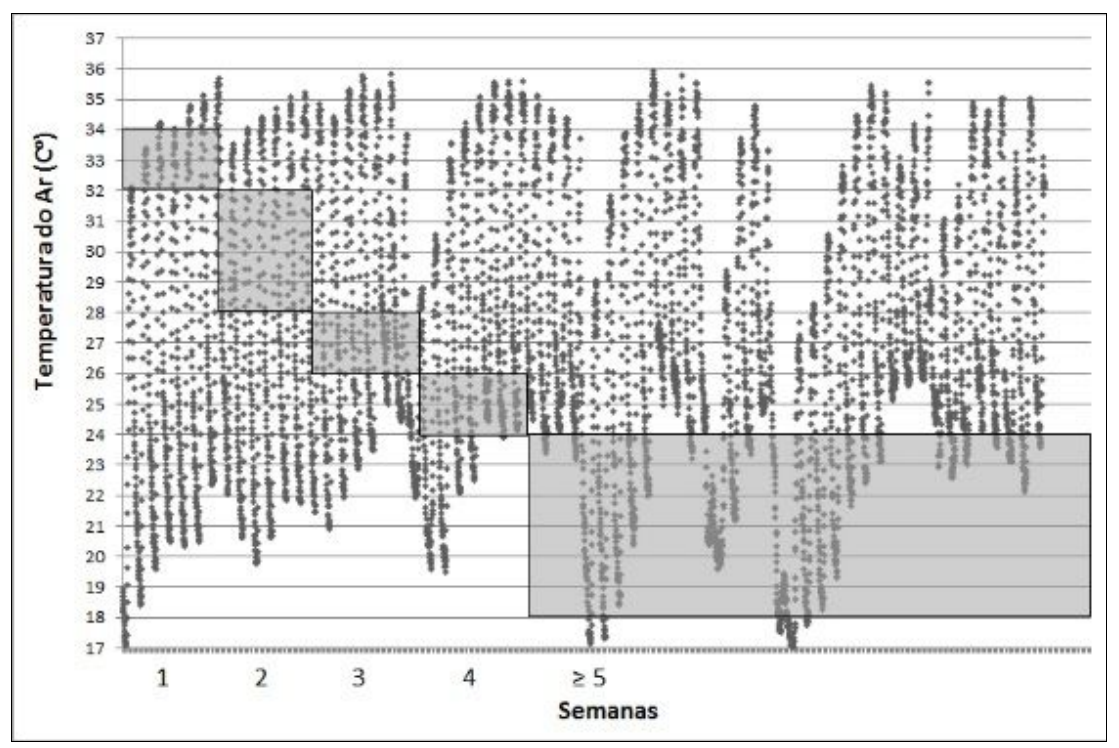

FIGURA 1. Temperatura do $\operatorname{ar}\left({ }^{\circ} \mathrm{C}\right)$ no interior do galpão, durante todo o período experimental.

Observa-se que a temperatura do ar oscilou durante o dia, fazendo com que as aves ficassem na faixa do conforto térmico, somente num intervalo estreito do tempo. Na primeira semana, as aves sofreram mais com estresse por frio, ficando a maior parte do tempo submetida às temperaturas inferiores $32{ }^{\circ} \mathrm{C}$. Observa-se também, na primeira semana e em determinados períodos, temperaturas superiores ao limite recomendado de $34{ }^{\circ} \mathrm{C}$ (SCHIASSI et al., 2015), podendo induzir 
hipertermia com desidratação nos pintinhos, levando a redução no consumo de ração e atraso no crescimento (CORDEIRO et al., 2010).

Segundo Cordeiro et al. (2010), as aves nos primeiros dias de vida expostas às temperaturas baixas e fora da zona de conforto térmico, poderão apresentar menor ganho de peso, de difícil recuperação nas fases de crescimento e engorda, além de resultar em desuniformidade do lote.

$\mathrm{Na}$ segunda e terceira semanas de vida das aves, a condição de estresse por frio vai diminuindo, sendo que a partir da quarta semana, observa-se situações de intenso estresse calórico. A queda no consumo de ração pelas aves e a produção de carne estão intimamente relacionadas com as condições térmicas ambientes (CASSUCE et al., 2013; SCHIASSI et al., 2015).

De acordo com Baêta e Souza (2010), o ambiente considerado confortável para frangos adultos com 35 dias, apresenta temperatura entre 18 a $28{ }^{\circ} \mathrm{C}$, sendo a temperatura crítica inferior aos $15^{\circ} \mathrm{C}$ e temperatura crítica superior aos $32^{\circ} \mathrm{C}$. A umidade relativa do ar ideal varia entre 50 e 70\% (TINÔCO, 2001).

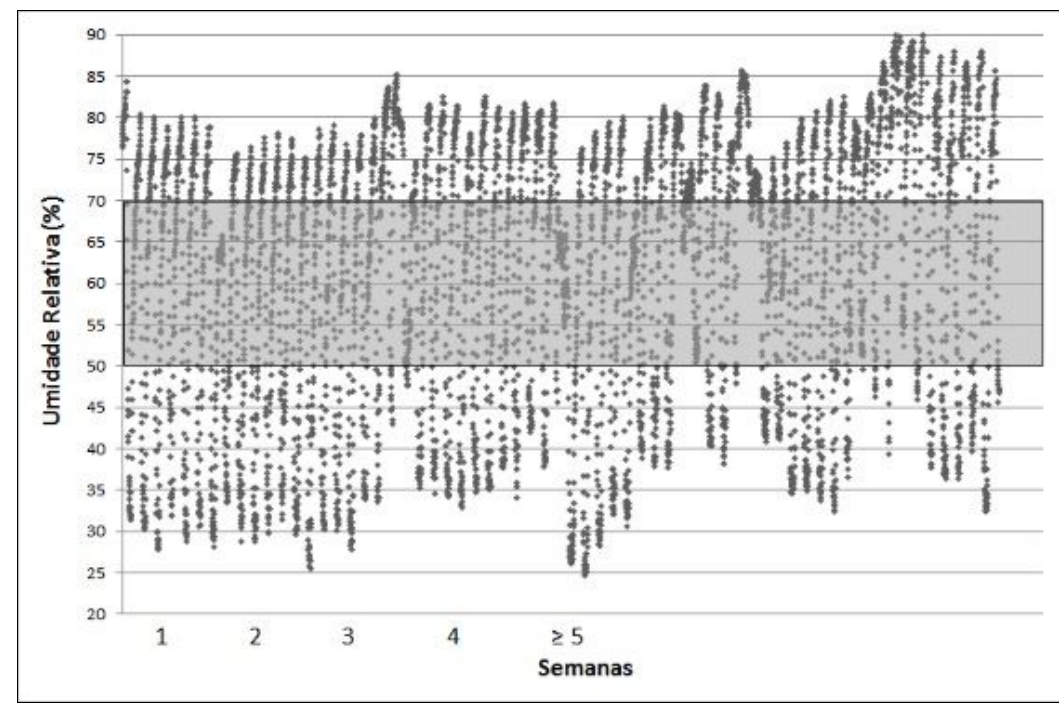

FIGURA 2. Umidade relativa do ar (\%) no interior do galpão, durante todo o período experimental.

Observa-se uma grande oscilação relacionada à umidade relativa do ar. O período experimental de julho a setembro é caracterizado como verão amazônico, no qual se destaca por ser um período com média a baixa pluviosidade. Por isso, pode-se observar a ocorrência de valores de até $25 \%$ de umidade relativa do ar.

Valores de umidade superiores a $70 \%$ têm relação inversa com a perda de calor (TINÔCO; GATES, 2005). Quanto maior a umidade relativa, maior a dificuldade da ave em perder calor latente por evaporação, comprometendo o seu desenvolvimento produtivo. Os resultados de desempenho zootécnico dos frangos de corte estão apresentados na Tabela 1. 
TABELA 1 - Peso vivo e consumo de ração acumulados e conversão alimentar, eficiência e viabilidade, segundo a linhagem de frangos de corte, avaliados em cada período $\left(^{*}\right)$.

\begin{tabular}{|c|c|c|c|c|c|c|c|c|c|c|}
\hline & & & & & Períod & o (dias) & & & & \\
\hline & $1-7$ & $1-1$ & & $1-21$ & $1-28$ & $1-35$ & $1-42$ & $1-49$ & $1-56$ & $1-63$ \\
\hline Linhag & & & & & Peso Vi & $10(\mathrm{Kg})$ & & & & \\
\hline Cobb & 0,09 & 0,20 & & $0,38^{\mathrm{a}}$ & $0,60^{\mathrm{a}}$ & $0,78^{\mathrm{a}}$ & $1,05^{\mathrm{a}}$ & $1,40^{\mathrm{a}}$ & $1,72^{\mathrm{a}}$ & $2,12^{a}$ \\
\hline Ross & 0,09 & 0,19 & & $0,35^{\mathrm{b}}$ & $0,55^{\mathrm{b}}$ & $0,70^{\mathrm{b}}$ & $0,95^{\mathrm{b}}$ & $1,28^{\mathrm{b}}$ & $1,60 \mathrm{~b}$ & $1,98^{\mathrm{b}}$ \\
\hline CV $(\%)$ & 4,64 & 5,75 & & 7,99 & 9,48 & 11,24 & 10,18 & 9,73 & 9,05 & 7,55 \\
\hline & & & & & nsumo & e Ração & $(\mathrm{Kg})$ & & & \\
\hline Cobb & 0,10 & 0,32 & & 0,67 & $1,13^{\mathrm{a}}$ & $1,72^{\mathrm{a}}$ & $2,40^{\mathrm{a}}$ & 3,19 & $4,05^{\mathrm{a}}$ & 5,18 \\
\hline Ross & 0,09 & 0,31 & & 0,63 & $1,05^{\mathrm{b}}$ & $1,56^{\mathrm{b}}$ & $2,14^{b}$ & 2,96 & $3,74^{b}$ & 4,83 \\
\hline CV (\%) & 6,33 & 6,19 & & 7,49 & 8,78 & 11,43 & 10,73 & 11,5 & 8,16 & 9,41 \\
\hline & & & & & Conversâ & o Alimen & tar & & & \\
\hline Cobb & 1,00 & 1,61 & & 1,76 & 1,88 & 2,20 & 2,28 & 2,27 & 2,35 & 2,43 \\
\hline Ross & 1,00 & 1,58 & & 1,79 & 1,90 & 2,23 & 2,26 & 2,30 & 2,33 & 2,43 \\
\hline $\mathrm{CV}(\%)$ & 3,78 & 3,26 & & 3,22 & 4,22 & 7,21 & 8,43 & 7,75 & 6,94 & 6,89 \\
\hline & & & & & & & & & (cont & nuação) \\
\hline & & & & & Perío & lo (dias) & & & & \\
\hline Linhag & & & & & ciência & limentar & (\%) & & & \\
\hline Cobb & & 99,8 & 62,1 & & $8 \quad 52$ & 45,4 & 43,9 & 44,1 & 42,7 & 41,1 \\
\hline Ross & & 100 & 63,1 & & 52 & 45,0 & 44,5 & 43,5 & 43,0 & 41,2 \\
\hline CV $(\%)$ & & 3,80 & 3,20 & & 4,1 & 6,65 & 8,16 & 8,19 & 7,73 & 6,88 \\
\hline & & & & & Viabili & dade (\%) & & & & \\
\hline Cobb & & 100 & 99 & 9 & 99 & 95 & 95 & 95 & 95 & 92 \\
\hline Ross & & 100 & 100 & 9 & 97 & 95 & 92 & 92 & 91 & 88 \\
\hline CV $(\%)$ & & 100 & 100 & 9 & 97 & 95 & 92 & 92 & 91 & 88 \\
\hline
\end{tabular}

$\left({ }^{*}\right)$ Médias seguidas de letras diferentes na coluna, diferem significativamente entre si, pelo teste $\mathrm{F}$ ao nível de $5 \%$ de probabilidade.

As aves da linhagem Cobb apresentaram maior peso vivo aos 21 dias de idade até o período final de criação, quando comparados aos da linhagem Ross. Este dado infere que as aves da linhagem Cobb apresentam um crescimento inicial semelhante às aves da linhagem Ross e que, posteriormente, apresentam um ganho evidenciado pelo crescimento superior e pela diferença significativa até o final do período experimental. Esses resultados confirmaram os já relatados por Tona et al. (2010), que observaram maior precocidade na taxa de crescimento de frangos da linhagem Cobb quando comparados com os da linhagem Ross.

No geral, um padrão diferencial de desenvolvimento entre as duas linhagens pode estar relacionado a diferenças no processo de eclosão e crescimento pós-natal precoce (TALEBI et al., 2005). Stringhini et al. (2003), avaliaram o desempenho zootécnico das linhagens Ross, Cobb, Arbor Acres e Avian Farms, concluindo que não houve efeito da linhagem no peso das aves nos períodos avaliados.

Diferenças no peso vivo entre linhagens foram observadas por, Garcia Neto e Campos (2004), constataram que as aves da linhagem Cobb, cujo peso inicial de pintinhos no alojamento foi maior, não mantiveram diferença favorável inicial apresentando menor peso ao término do experimento, comparada à da linhagem Ross. 
O consumo de ração foi superior para as aves da linhagem Cobb nos períodos de 28, 35, 42 e 56 dias. Observa-se que o consumo no período final de criação (Tabela 1), das aves, $5,185 \mathrm{Kg}$ e 4,830 Kg, Cobb e Ross, respectivamente, estão abaixo do recomendado $7,451 \mathrm{Kg}$, conforme o Suplemento (2013). Dessa forma, pode-se inferir que o consumo de alimentos se correlaciona negativamente com a temperatura ambiente, haja vista, que as aves reduzem a ingestão de alimentos na tentativa de diminuir o calor gerado pelos processos metabólicos (PONCIANO et al., 2012).

Os dados desse estudo referentes ao consumo de ração, corroboram com a pesquisa de Dalólio et al. (2016), que caracterizando as condições bioclimáticas de um galpão experimental de frangos de corte, verificaram que as aves não permaneceram em conforto térmico durante todo o período de criação, apresentando desempenho zootécnico abaixo do esperado, com consumo de ração de $4,188 \mathrm{Kg}$ aos 42 dias de idade.

Santos et al. (2005), compararam o crescimento, desempenho zootécnico, rendimento de carcaça e qualidade de carne de três linhagens de frango de corte: Cobb, Paraíso Pedrês e ISA Label. Quanto ao desempenho zootécnico, observaram que a linhagem Cobb apresentou maior ganho de peso e consumo de ração em todos os períodos. O alto consumo de ração de linhagens melhoradas é atribuído à maior demanda de nutrientes para atender ao maior potencial de ganho de peso destas linhagens.

A conversão alimentar das aves foi ruim, ocorrendo uma piora no desempenho zootécnico, pois o consumo não foi correspondente no ganho de peso. Para produção de cada quilo de frango, foram necessários $2,43 \mathrm{Kg}$ de ração. Dentre as possíveis causas de impacto na conversão alimentar do lote, os fatores climáticos podem ter prejudicado as aves desde a fase inicial, onde o consumo encontra-se abaixo do recomendado, conforme o Suplemento (2013). A alta umidade relativa aliada à alta temperatura do ar, são fatores climáticos que dificultam o processo de troca de calor das aves com o ambiente (CASSUCE et al, 2013).

Silva et al. (2009), avaliaram o desempenho de aves de linhagem Cobb alimentadas com ração sem suplementação em diversas temperaturas ambientes e constataram que a baixa temperatura provocou o pior resultado de conversão alimentar.

Assim como a conversão alimentar, o parâmetro de eficiência alimentar atesta o baixo desempenho das linhagens. À medida que aumentou a idade das aves, há redução da eficiência das aves no aproveitamento da ração. Esta redução pode ser devido a primeira etapa de utilização do alimento, apresentar digestibilidade alimentar mais baixa (OLIVEIRA et al., 2006; SCHIASSI et al., 2015), tendo como resultado uma relação de conversão alimentar pior. Acredita-se que devido à exposição de frangos ao estresse térmico por calor, essas condições se agravam.

Resultados semelhantes de diminuição na eficiência alimentar de frangos de corte foram observados por Lana et al. (2000), que verificaram que os dados de eficiência só diminuíram nos casos em que temperatura e umidade são elevadas.

Não houve efeito significativo $(P>0,05)$ entre as linhagens para o índice de viabilidade. Silva et al. (2017) compararam a viabilidade criatória de linhagens comerciais e notaram maiores índices nos machos, além de apresentaram melhores desempenhos e características de carcaças do que as fêmeas.

O baixo desempenho das aves desde a fase inicial, leva a conclusão de que a dieta basal consumida pelas aves no período inicial de criação, não 
foi suficiente para maximizar o desempenho zootécnico em condições de baixas temperaturas. No que se refere à formulação da ração o teor de proteína bruta de $20 \%$ para a fase inicial.

Quando as aves são expostas a um ambiente com baixa temperatura, uma forma de compensar é consumindo mais proteína do que teoricamente precisam, catabolizando o excesso de alguns aminoácidos que resultaram na produção de calor metabólico. A partir da terceira semana de vida, as aves foram submetidas a um maior estresse calórico, sendo que a dieta nesta fase apresentou $18 \%$ de PB. Neste caso, o calor contribuiu para a diminuição do consumo de ração, fazendo com que as aves não conseguissem suprir suas necessidades proteicas.

Vasconcellos et al. (2012), observaram uma piora no desempenho de frangos de corte de linhagem Ross com a redução proteica das rações, ocorrendo um efeito decrescente sobre o ganho de peso, o peso final e o consumo, além de piora na conversão alimentar, à medida que diminuía os níveis de proteína bruta.

Entretanto, Oliveira et al. (2010), ao avaliarem os efeitos de cinco níveis de proteína bruta em rações (21,6\%; $20,6 \% ; 19,6 \% ; 18,6 \%$ e $17,6 \%)$, para frangos de corte da linhagem Cobb em ambiente de estresse por calor de 22 a 42 dias de idade, constataram que não houve efeito sobre as características de desempenho zootécnico, nem sobre o peso absoluto e o rendimento de cortes nobres, indicando a redução de proteína bruta de 21,6 até $17,6 \%$.

Verificou-se que as linhagens criadas não apresentaram diferenças significativas $(P>0,05)$ no rendimento de Carcaça (Car), Cobb $(75,09 \%)$ e Ross (71,85\%) (Tabela 2).

TABELA 2 - Rendimento de carcaça, vísceras, gordura abdominal e cortes nobres ${ }^{(1)}$.

\begin{tabular}{|c|c|c|c|c|c|c|c|c|c|}
\hline \multicolumn{10}{|c|}{ Rendimento (\%) } \\
\hline & Car & $\mathbf{M}$ & C & $\mathbf{F}$ & I & GA & $C x$ & Sc & $\mathbf{P}$ \\
\hline Cobb & 72,72 & 2,27 & 0,71 & 2,77 & 5,66 & 3,51 & 14,48 & 15,94 & 25,27 \\
\hline Ross & 71,85 & 2,46 & 0,81 & 2,77 & 5,66 & 3,70 & 13,92 & 16,46 & 24,40 \\
\hline $\mathrm{CV}(\%)$ & 2,72 & 18,45 & 15,85 & 15,41 & 9,86 & 13,69 & 6,48 & 8,30 & 8,72 \\
\hline
\end{tabular}

${ }^{(1)}$ Médias seguidas de letras iguais na coluna, não diferem significativamente entre si, pelo teste $\mathrm{F}$ ao nível de $5 \%$ de probabilidade.

Car: Carcaça; M: Moela; C: Coração; F: Fígado; I: Intestino; GA: Gordura abdominal; Cx: Coxa; Sc: Sobrecoxa e P: Peito.

O rendimento das vísceras comestíveis, Moela $(\mathrm{M})$, Coração $(\mathrm{C})$, Fígado $(\mathrm{F})$, Intestino (I) e gordura abdominal e cortes nobres, Coxa (Cx), Sobrecoxa (Sc) e Peito (P) também não apresentaram diferenças $(P>0,05)$, portanto, não foram influenciadas pelos grupos genéticos. Os dados desse estudo, corroboram a Stringhini et al. (2003), que avaliaram quatro linhagens de frango de corte, não verificaram o efeito da linhagem nos parâmetros rendimento de carcaça ou de cortes. Contudo, esses dados diferem do estudo de Oliveira et al. (2006), que observaram a influência negativa do calor sobre os pesos absolutos de coxa, sobrecoxa e peito, sendo mais agravante, quando esses efeitos são associados ao aumento da umidade relativa do ar.

Marcato et al. (2010), observaram que não houve influência da linhagem nas taxas de crescimento e deposição de nutrientes no coração. As aves de linhagem Ross apresentaram maior atividade metabólica 
na digestão e síntese de nutrientes com precocidade no crescimento e a linhagem Cobb foi mais precoce no desenvolvimento do intestino e crescimento.

O comportamento, a reprodução e a produção de carne e ovos estão relacionados às condições térmicas ambientais (OLIVEIRA et al., 2006; BROSSI et al.; 2009; CASSUCE et al., 2013). Sugere-se que as condições ambientais prejudicaram o desempenho produtivo das aves, ocasionando o aumento de dias para chegar ao peso de abate, diminuição da ingestão de ração e piora na conversão alimentar, haja vista, que parte dos nutrientes foi desviada para manutenção da homeotermia.

\section{CONCLUSÃO}

O desempenho zootécnico e o rendimento dos frangos de corte de ambas as linhagens mostraram-se inferior ao esperado. Temperaturas inferiores à de conforto durante as primeiras semanas e temperaturas superiores à de conforto nas semanas subsequentes, associadas a grande oscilação da umidade relativa do ar, prejudicaram o desempenho zootécnico e o rendimento produtivo de frangos de corte.

\section{REFERÊNCIAS}

API, I.; TAKAHASHI, S.E.; MENDES, A.S.; PAIXÃO, S.J.;REFATI, R.; RESTELATTO, R.;Efeito da sexagem e de linhagens no desempenho e rendimento de carcaça de frangos de corte. Revista Ciência Animal Brasileira, v.18, p.1-10, e32691, 2017. Disponível em: <http://www.scielo.br/pdf/cab/v18/1809-6891-cab-18e32691.pdf>. doi: 10.1590/1089-6891v18e-32691

BAÊTA, F. C.; SOUZA, C. F. Ambiência em edificações rurais - conforto animal. Viçosa: UFV, 2010. 269 p.

BROSSI, C.; CONTRERAS-CASTILLO, C. J.; AMAZONAS E. A.; MENTEN, J. F. M. Estresse térmico durante o pré-abate em frangos de corte. Ciência Rural, v.39, n.4, p.1296-1305, 2009.

Disponível

em: <http://www.scielo.br/pdf/cr/v39n4/a145cr387.pdf>. doi:10.1590/ S010384782009005000039

CASSUCE, D. C.; TINOCO, I.F.F.; BAETA, F.C.; ZOLNIER, S.; CECON, P.R.; VIEIRA, M.F.A.; Thermal comfort temperature update for broiler chickens up to 21 days of age. Engenharia Agrícola, v.33, n.1, p.28-36, 2013. Disponível em: <http://www.scielo.br/pdf/eagri/v33n1/v33n1a04.pdf>.

doi:10.1590/S010069162013000100004

CORDEIRO, M. B.; TINOCO, I.F.F.; SILVA, J.N.; VIGODERIS, R.B.; PINTO, F.A.C.; CECON, P.R; ;Conforto térmico e desempenho de pintos de corte submetidos a diferentes sistemas de aquecimento no período de inverno. Revista Brasileira de

Zootecnia, v.39, n.1, p.217-224, 2010. Disponível em: <http://www.scielo.br/pdf/rbz/v39n1/29.pdf>. doi:10.1590/S151635982010000100029

DA COSTA, M. J.; ZARAGOZA-SANTACRUZ, S.; FROST, T. J.; HALLEY, J.; PESTI, G. M. Straight-run vs. sex separate rearing for 
2 broiler genetic lines Part 1: Live production parameters, carcass yield, and feeding behavior. Poultry Science, v.96, n.8, p. 2641-2661, 2017. Disponível em: <https://www.ncbi.nlm.nih.gov/pubmed/28339997>. doi:10.1093/japr/15.3.362

DALÓLIO, F. S.; MOREIRA, J.; COELHO, J. R.; SOUZA, C. F. Caracterização bioclimática de um galpão experimental de criação de frangos de corte na região de Diamantina-MG. Engenharia na agricultura, v.24, n.1, 2016. Disponível em: $<$ https://periodicos.ufv.br/ojs/reveng/article/view/585/395>. doi:10.13083/14143984/reveng.v24n1p22-31

FERREIRA, D. F. Sisvar: a Guide for its Bootstrap procedures in multiple comparisons. Ciência e Agrotecnologia, v.38, n.2, p.109-112, 2014. Disponível em: <http://www.scielo.br/pdf/cagro/v38n2/a01v38n2.pdf>. doi:10.1590/S141370542014000200001

GARCIA NETO, M.; CAMPOS, E. C. Suscetibilidade de linhagens de frangos de corte à síndrome ascítica. Pesquisa Agropecuária Brasileira, v.39, n.8, p.803-808, 2004. Disponível em: <http://www.scielo.br/pdf/pab/v39n8/21742.pdf>. doi:10.1590/S0100-204X2004000800011

LANA, G. R. Q.; ROSTAGNO, H. S.; ALBINO, L. F. T.; LANA, A. M. Q. Efeito da temperatura ambiente e da restrição alimentar sobre o desempenho e a composição da carcaça de frangos de corte. Revista Brasileira de Zootecnia, v.29, n.4, p.11171123, 2000. Disponível em: <http://www.scielo.br/pdf/rbz/v29n4/5627.pdf>. doi:10.1590/S1516-35982000000400024

LI, M.; WU, J.; CHEN, Z. Effects of heat stress on the daily behavior of wenchang chickens. Brazilian Journal of Poultry Science, v.17, n.4, p.559-566, 2015. Disponível em: <http://www.scielo.br/pdf/rbca/v17n4/1516-635X-rbca-17-0400559.pdf>. doi:10.1590/1516-635X1704559-566

LITZ, F. H.; CARVALHO, C. M. C.; FERNANDES, E. A.; MARTINS, J. M. S.; FAGUNDES, N. S. Efeito de diferentes níveis de energia e proteína na ração sobre o desempenho de frangos de corte da linhagem cobb avian $48 \mathrm{TM}^{*}$. Veterinária Notícias Veterinary News, v.20, n.1, p.52-60, 2014. Disponível em: <http://www.seer.ufu.br/index.php/vetnot/article/view/23466>.

doi:10.14393/VTV20N1a2014.23466

MARCATO, S. M.; SAKOMURA, N. K.; FERNANDES, J. B. K.; SIQUEIRA, J. C.; DOURADO, L. R. B.; FREITAS, E. R. Crescimento e deposição de nutrientes nos órgãos de frangos de corte de duas linhagens comerciais. Revista Brasileira de Zootecnia, v.39, n.5, p.1082-1091, 2010. Disponível em: <http://www.scielo.br/pdf/rbz/v39n5/19.pdf>. doi:10.1590/S151635982010000500019

MARQUES, C.; MAGALHÃES JÚNIOR, A. P.; OLIVEIRA, F. Hidrogeomorfologia da ilha da trindade caracterização da única rede hidrográfica permanente nas ilhas oceânicas brasileiras. Os desafios da geografia física na fronteira do conhecimento. In: I Congresso Nacional de Geografia Física, Anais... p.4834- 
4845 ,

UNICAMP

2017.

Disponível

em:

<https://ocs.ige.unicamp.br/ojs/sbgfa/article/view/2500>.

doi:10.20396/sbgfa.v1i2017.2598

OLIVEIRA, R. F. M. DONZELE, J.L.; ABREU, M.L.T.; FERREIRA, R.A.; VAZ, R.G.M.V.; CELLA, P.S.; Efeitos da temperatura e da umidade relativa sobre 0 desempenho e o rendimento de cortes nobres de frangos de corte de 1 a 49 dias de idade. Revista Brasileira de Zootecnia, v.35, n.3, p.797-803, 2006. Disponível em: <http://www.scielo.br/pdf/rbz/v35n3/30072.pdf>.

doi:10.1590/S1516-

35982006000300023

OLIVEIRA, W. P.; OLIVEIRA, R.F.M.; DONZELE, J.L; ALBINO, L.F.T.; MARTINS, M.S.; MAIA, A.P.A.; Redução do nível de proteína bruta em rações para frangos de corte em ambiente de estresse por calor. Revista Brasileira de Zootecnia, v.39, n.5, p.1092-1098, 2010. Disponível em: <http://www.scielo.br/pdf/rbz/v39n5/20.pdf>. doi:10.1590/S1516-35982010000500020

PONCIANO, P. F.; YANAGI JUNIOR, L. S. T.; CAMPOS, A. T.; NASCIMENTO, J. W. B. Sistema fuzzy para predição do desempenho produtivo de frangos de corte de 1 a 21 dias de idade. Engenharia Agrícola, v.32, n.3, 2012. Disponível em: <http://www.scielo.br/pdf/eagri/v32n3/04.pdf >.

doi:10.1590/S010069162012000300004

ROSTAGNO, H. S. et al. Tabelas brasileiras para aves e suínos: composição de alimentos e exigências nutricionais. 3st ed. Viçosa: Editora UFV, DZO, 2011. 252 p.

SANTOS, A. L.; SAKOMURA, N.K.; FREITAS, E.R.; FONTES, C.M.L.S.; CARRILHO, E.N.V.M.; FERNANDES, J.B.K; Estudo do crescimento, desempenho, rendimento de carcaça e qualidade de carne de três linhagens de frango de corte. Revista Brasileira de Zootecnia, v.34, n.5, p.1589-1598, 2005. Disponível em: <http://www.scielo.br/pdf/rbz/v34n5/26640.pdf>. 35982005000500020 doi:10.1590/S1516-

SCHIASSI, L.; YANAGI JUNIOR, T.; FERRAZ, P.F.P.; CAMPOS, A.T.; SILVA, G.R.; ABREU, L.H.P.; Comportamento de frangos de corte submetidos a diferentes ambientes térmicos. Engenharia Agrícola, v.35, n.3, p.390-396, 2015. Disponível em: <Comportamento de frangos de corte submetidos a diferentes ambientes térmicos>. doi:10.1590/1809-4430-Eng.Agric.v35n3p390-396/2015

SCHIASSI, L.; YANAGI JUNIOR, T; REIS, G.M.; ABREU, L.H.P.; CAMPOS, A.T.; CASTRO, J.O.; Modelagem Fuzzy aplicada na avaliação do desempenho de frangos de corte. Revista Brasileira de Engenharia Agricola e Ambiental-Agriambi, v.19, n.2, p.140-146, 2015. Disponível em: <http://www.scielo.br/pdf/rbeaa/v19n2/14154366-rbeaa-19-02-0140.pdf>. doi:10.1590/1807-1929/agriambi.v19n2p140-146

SILVA, M.T.P; VELOSO, R.C.; PIRES, A.V.; TORRES FILHO, R.A.; PINHEIRO, S.R.F.; WINKELSTROTER, L.K. et al. Desempenho e características de carcaça de três genótipos comerciais de frangos de corte alimentados com 
diferentes dietas. Arquivo Brasileiro de Medicina Veterinária e Zootecnia, v.69, n.5, pp.1311-1318, 2017. Disponível em: <http://www.scielo.br/pdf/abmvz/v69n5/0102-0935-abmvz-69-05-01311.pdf>. doi:10.1590/1678-4162-8241

SILVA, V. K.; SILVA, J.D.T.; GRAVENA, R.A.; MARQUES, R.H.; HADA, F.H.; MORAES, V.M.B.Desempenho de frangos de corte de 1 a 21 dias de idade alimentados com rações contendo extrato de leveduras e prebiótico e criados em diferentes temperaturas. Revista Brasileira de Zootecnia, v.38, n.4, p.690-696, 2009. Disponível em: <http://www.scielo.br/pdf/rbz/v38n4/15.pdf>. doi:10.1590/S1516-35982009000400015

STRINGHINI, J. H.; LABOISSIÉRE, M.; MURAMATSU, K.; LEANDRO, N. S. M.; CAFÉ, M. B. Avaliação do desempenho e rendimento de carcaça de quatro linhagens de frangos de corte criadas em Goiás. Revista Brasileira de Zootecnia, v.32, n.1, p.183-190, 2003. Disponível em: <http://www.scielo.br/pdf/rbz/v32n1/16091.pdf>. doi:10.1590/S151635982003000100023

SUPLEMENTO: desempenho e nutrição para frangos de corte. Cobb500: Metas de desempenho [Internet]. 2013. Disponível em: <http://www.cobbvantress.com/languages/guidefiles/793a16cc-5812-4030-94361e5da177064f_pt.pdf> Acesso em: 14 maio 2019

TALEBI, A.; ASRI-REZAEI, S.; ROZEH-CHAI, R.; SAHRAEI, R. Comparative studies on haematological values of broiler strains (Ross, Cobb, Arbor-acres and Arian). International Journal of Poultry Science, v.4, n.80, p.573-579, 2005. Disponível em: $<$ https://scialert.net/abstract/?doi=ijps.2005.573.579>. doi:10.3923/ijps.2005.573.579

TINÔCO I. F. F. Avicultura industrial: novos conceitos de materiais, concepções e técnicas construtivas disponíveis para galpões avícolas brasileiros. Revista Brasileira de Ciência Avícola, v.3, n.1, p.1-26, 2001. Disponível em: $<$ http://www.scielo.br/scielo.php?script=sci arttext\&pid=S1516$635 \times 2001000100001 \& \operatorname{lng}=$ en\&nrm=iso\&tlng=pt>.

doi:10.1590/S1516$635 \times 2001000100001$

TINÔCO, I. de F. F.; GATES, R. S. Manejo de matrizes de corte. Editado por Marcos Macari e Ariel Antônio Mendes - Campinas: FACTA, 421p. p.18-19, 2005.

TONA, K.; ONAGBESAN, O.M.; KAMERS, B.; EVERAERT, N.; BRUGGEMAN, V.; DECUYPERE, E.; Comparison of Cobb and Ross strains in embryo physiology and chick juvenile growth. Poultry science, v.89, n.8, p.1677-1683, 2010. Disponível em: <https://www.ncbi.nlm.nih.gov/pubmed/20634523>. doi:10.3382/ps.2009-00386

VASCONCELLOS, C. H. F.; FONTES, D.O.; CORREA, G.S.S.; VIDAL, T.Z.B. SILVA, M.A. et al. Efeitos da redução da proteína dietética sobre o desempenho e as características de carcaça de frangos de corte de 1 a 21 dias de idade. Revista Brasileira de Zootecnia, v.41, n.3, p.662-667, 2012. Disponível em: 
$<\mathrm{http}: / /$ www.scielo.br/pdf/rbz/v41n3/28.pdf >.

doi:10.1590/S151635982012000300028 